\title{
FEM Analysis of the Different Spinning Speeds of Inner Groove Copper Tube Formed
}

\author{
Shigang Wang \\ School of Mechatronics Engineering, Qiqihar University \\ Qiqihar, China \\ hljwangsg@163.com
}

\begin{abstract}
Aiming to explain forming mechanism of copper pipe workpiece with inner groove copper tube via ball-rolling at different spinning speeds, the copper pipe workpiece and straight die is modeled in ABAQUS. And the whole simulation includes forming process, analysis of strain and stress. It is concluded that in the process of ball-rolling, the deformation of copper pipe workpiece is mainly the axial and teeth groove radial; with rotary extrusion increasing, the equivalent strain and stress enlarge gradually. Under the premise of keeping the quality of production, the maximum spinning speeds is $24000 \mathrm{r} / \mathrm{min}$, which will not lose steady and complete the whole operation successfully. The simulation data and conclusion supply the basis for the actual processing.
\end{abstract} pipe

Keywords-finite element; ball spinning; inner spiral copper

\section{INTRODUCTION}

Inner Spiral copper pipe which has an internal spiral fins. With air conditioners, refrigerators refrigeration appliance to promote the application, how to improve the heat exchange efficiency, reducing energy consumption is an issue that be considered by manufacturers. Similarly, in the electronics industry, electronic device chip damage due to the imbalance of high heat flux and residual stresses caused. Inner spiral copper pipe can become the efficient energysaving device of air conditioning and refrigerator. It also can become the ideal component density high heat in electronic device. Its efficient heat transfer principle is the special structure of the suction flow core can cause separation the boundary layer separation of flowing medium spiral flow, prompting the degree of turbulence intensified. Thread fin structure while increasing the internal surface area to improve the thermal conductivity of $20 \%$ to $30 \%$ than the light pipe walls, reducing energy consumption by $15 \%$. Therefore, high-value-added products such attention has been paid, as early as the 1970s began abroad will be applied to the air conditioner, while China until in the late 1980s began to develop technology and equipment, and in the 21st century access to a wide range of applications.

Our spinning technology developed in the late 1960s, and after many years of unremitting efforts, has been a more significant development [1]. In our country, the research unit of spinning technology is military enterprise, college institute and scientific research institute. In the country with a hundred units of the spinning machine, with about 500 large spinning equipment, engaged in spinning

\author{
Boyu Zhao \\ School of Mechatronics Engineering, Qiqihar University \\ Qiqihar, China \\ 542214656@qq.com
}

technology research personnel nearly a thousand. From the first session of the National Spinning Technology Exchange Conference in 1977, it has been nearly 30 years of history, three January session of spinning academic annual meeting had been held in the $9^{\text {th }}$. The National Spinning Academic Committee, established in 1981 has been 24 years of history, under the guidance of Chinese Mechanical Engineering Society (forging) Plastic Engineering Society, so spinning technology has made great progress. Nearly 30 years time, the rapid momentum of domestic spinning technology, From the 60 time with weapons and aviation as the main spinning product for indepth research, and gradually promote the development of thin spinning technology more indepth. Since spinning thinning effect for ming region is being more compressive stress, which makes the mechanical strength of the molded product and the accuracy has been significantly improved, and then developed by the Electric-hydraulic control of spinning equipment. After that, spin forming technology has been extended to the electronics, nuclear and weapons and other fields [2].

The ball spinning process as a new technology starts from the early 1960s. After decades of effort, it has obtained great development. The process is used in the instrumentation bellows elastic element of thin-walled tube processing in Shanghai and Shenyang. Until the early 70s, the ball spinning technology was gradually, extended to military industry, aerospace, electronics, medical equipment and civil air conditioning; to process the high precision, thin wall thickness, different departments need small diameter pipe parts of a class. Spinning processing technology is mature.

Because of the rapid development of computer technology and the finite element analysis technology, spinning process technology is gradually from theory research to the $3 \mathrm{D}$ simulation research, spinning processing technology is also obtained the further development. Shuyong Jiang [3-6], analysis the forming process of thinwalled tube in the longitudinal reinforcement, reveals the inner rib forming principle of spinning parts. Mao-Sheng $\mathrm{Li}$ [7] use the state of plane circle arc punch indentation of semi infinite body when the mean contact pressure to calculate process in forming pressure in the contact area method, discussed the relationship between the average contact pressure of the steel ball and the contact pressure when the steel ball spinning, and study the characteristics of arc punch indentation of semi infinite circular body under the plane strain state of contact stress. 
Wu Jiang et al. [8] by adjusting the feed rate and thinning rate of stainless steel tube in the spinning process. Wang Miao [9] uses a finite element numerical simulation method, studies the variation of axial feed ratio and the forming law of the workpiece in different die speeds, analysis the law of stress and strain, gives thin wall pipe in ball spinning forming when the feed ratio. From the study we can see, research emphasis from ordinary light tube spinning force analysis and process parameters on the fitting quality gradually turned to the influence of stress distribution and forming process more complex rifled tube forming research. Jin-song Liu and Neng-yong Ye use finite element software MSC. Marc, according to the machining process parameters established TP2 finite element model of ball spinning of inner grooved copper tube processing, analysis the defects and reasons of forming. The results show that, increasing the thread core head of addendum and reduce the pipe wall thickness and fillet can increase the curvature of the addendum arc, avoid the formation of forming defects [10].

Based on the modern basic theory of finite element simulation and finite element analysis software ABAQUS, take numerical simulation to ball spinning of inner grooved copper tube forming process, gets the ball spinning of inner grooved copper tube forming process, and emphatically analyzes the internal inner groove copper tube under different spinning speed of stress and strain distribution, in order to work out high quality in the process of production of inside inner groove copper tube.

\section{THE PRINCIPLE AND ANALYSIS OF INNER GROOVE COPPER TUBE FORMING PROCESS}

\section{A. Inner Groove Copper Tube Thread Brass Molding Process Principles}

Ball spinning process of inner threads copper tube comprises three times: reducing the drawing, spinning thread groove and sizing drawing forming [11]. The forming process is shown in Fig. 1, the tube interior into an axial can rotate freely, outer surface with a screw groove cord head, which can rotate around the axis of rotation of the copper free floating plug connection through the connecting rod and the. The process of drawing, moving core to axial positioning function for the threaded mandrel. Spinning groove after the brass by the final sizing stretching into internal thread brass specifications.

Before forming the pipe blank, for the annealed light tube, first of all, through the floating mandrel diameter reduction of drawing, but traveling core head due to the axial force and different from the usual thinning, reducing floating mandrel drawing, the drawing force requirements as small as possible. After reducing the drawing, the annealing pipe work hardening, yield increased significantly, and then into the ball spinning. Ball spinning is core of the whole process, directly determines the internal thread tube into the tooth quality, it is the key to improvement and optimization technology. However, ball spinning forming process is complex, the inner surface of the tube provided with thread core and floating mandrel is connected, in a floating state, the outer surface of a ball high speed spinning. In practical machining ball rotates and moves around the sun, friction between ball, ring and tube blank made the ball's rotation can be arbitrary; revolution axis is the axis of the tube. We can see from the above, including the process of spinning, drawing and extrusion process of ball spinning, deformation is complex, and the ball and the thread core in a complex interactive motion state, so it is necessary to reproduce the forming process by computer technology, research on the forming law of system theory, process optimization and improvement, improve product quality.

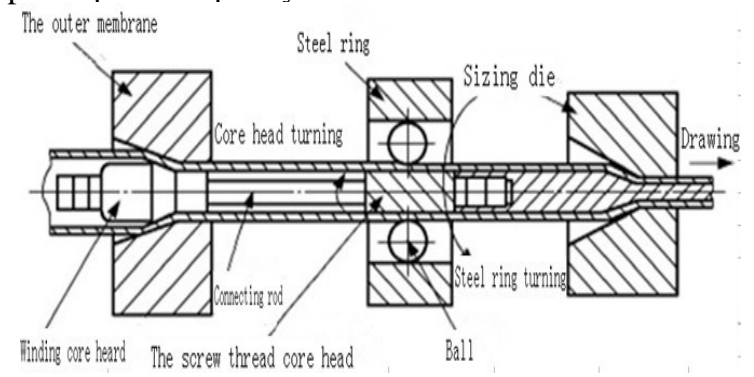

Figure 1. Forming schematic of inner groove copper tubes

\section{B. Determine the Equations of Motion of the Balls}

In the process of ball spinning of inner grooved copper tube ball movement is a complex space curve, ball in the ball mold leads to the angular velocity, around the copper billet tube axis of revolution. At the same time, the ball itself with internal inner groove copper tube outside surface contact with each other and with angular rotation. In the actual machining process, due to the effect of the axial drawing force, ball orbit rotates plane is a plane and Angle, but considering the axial drawing speed is relatively small, therefore, the simulation will be the Angle is set to zero, so assume that ball orbit plane and rotation in the same plane, and the same rotation.

In fact, ball spinning processing, the ball around the internal inner groove copper tube anti-clockwise revolution, the ball with that of the inside inner groove copper tube outside surface friction also counterclockwise rotation, as shown in Fig. 2. Assuming that the initial state of the ball and inner groove copper tube contact points respectively $A_{0}$ and $B_{0}$ without regard to the balls $O_{1} B_{0}$ of its autobiography, the radius of the position at the next moment will move to the $O_{1} B_{2}$ position shown in Fig 2 . Due to the rotation of the ball, the next time the contact points are in $A_{1}$ and $B_{1}$. Ideally, pure rolling contact between the balls and the outer surface of the inner groove copper tube. Therefore, it must be equal to the arc length $A_{0} A_{1}$ and arc length $B_{0} B_{1}$, then $\theta=\left(R_{0} / \rho+1\right) \alpha$. If the ball around the inner grooved copper tube angular velocity is $\omega_{r}$, the ball around the center of the sphere for the angular velocity $\omega_{a}$ is 


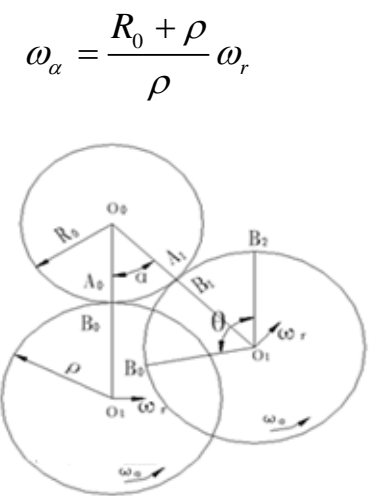

Figure 2. Schematic diagram of ball trajectories

Including inner groove copper tube dimensional finite element model. This will be the center of the ball in the center position of the rigid body. Centroid and the actual angular velocity $\omega_{0}$ about the copper base tube axis do cylindrical spiral motion. While setting rigid body around the centroid of the compensation angular velocity is $\omega_{1}$. Two angular velocity and the same direction, Finite element numerical simulation can be implemented at any time, the contact position of the ball and inner groove copper tube consistent with the actual situation.

In order to achieve precise control of the ball position, we need four variables: Three positional coordinates of the centroid $X, Y, Z$ and rigid body with respect to the centroid rotational angular velocity $\omega_{\alpha}$. Position coordinates $X, Z$ for control the ball centroid position and a radially feed; $Y$ is used to control the axial feed of ball. $\omega_{\alpha}$ is the rotation angular velocity of the ball, by the spindle speed $n$ and ball radius $\rho$, thread brass radius $R_{0}$, to ensure that between the ball and inner grooved copper tube for the pure rolling contact condition. These variables area function of time using the following mathematical formula description.

$$
\begin{gathered}
x=\left(R_{0}+\rho-\Delta\right) \sin \left(\frac{n_{0} \pi}{30} t\right) \\
y=\left(R_{0}+\rho-\Delta\right) \cos \left(\frac{n_{0} \pi}{30} t\right) \\
z=\frac{n_{0} f t}{60} \\
\omega_{\alpha}=\frac{n_{0} \pi}{30}\left(\frac{R_{0}+\rho}{\rho}\right) t
\end{gathered}
$$

Among them $R_{0}, \rho, n_{0}, f, \Delta$ for the inner grooved copper tube is the initial outer radius, ball radius, spindle speed, ball axial feed rate and nominal amount of depression.

\section{THE ESTABLISHMENT OF FINITE ELEMENT MODEL}

\section{A. Establishing Material Models}

This chapter focuses on the inner grooved copper tube wall screw groove spinning process. Material model for the simulation results have an important impact. The copper billet tubes of ball spinning are hard state copper tubes after the necking drawing, so in this chapter, according to the national standard pipe tensile test and the relevant data are obtained, such as Table 1, 2. In the finite element model of the core head and the ball three-dimensional analytic set of rigid.

TABLE I. MATERIAL PROPERTIES OF THE INNER GROOVE COPPER TUBE

\begin{tabular}{|c|c|c|c|}
\hline & $\begin{array}{c}\text { Modulus of } \\
\text { Elasticity /GPa }\end{array}$ & Poisson Ratio & $\begin{array}{c}\text { Density } \\
\mathrm{g} / \mathrm{cm}^{3}\end{array}$ \\
\hline Numerical & 118.5 & 0.3 & 8.96 \\
\hline
\end{tabular}

TABLE II. MODEL PARAMETERS OF THE INNER GROOVE COPPER TUBE JOHNSON-COOK

\begin{tabular}{|c|c|c|c|c|c|c|c|}
\hline $\begin{array}{c}\text { Material } \\
\text { Science }\end{array}$ & $\begin{array}{c}\mathrm{A} \\
(\mathrm{Mpa})\end{array}$ & $\begin{array}{c}\mathrm{B} \\
(\mathrm{MPa})\end{array}$ & $\mathrm{n}$ & $\mathrm{C}$ & $\mathrm{m}$ & $\begin{array}{c}\text { Melting } \\
\text { Point }\end{array}$ & $\begin{array}{c}\text { Over } \\
\text { Temperatu } \\
\text { re }\end{array}$ \\
\hline $\begin{array}{c}\text { Inner } \\
\text { Groove } \\
\text { Copper } \\
\text { Tube }\end{array}$ & 227 & 376 & 0.207 & 0.1743 & 1.09 & 1356 & 298 \\
\hline
\end{tabular}

B. Finite Element Model of the Inner Grooved Copper Tube

Ball spinning process, the number of balls is usually around 4. Ball spinning process is an incremental forming, from the inner grooved copper tube cross-section can be observed in each of the recesses are several ball-shaped joint action. In this paper, the forming process simulation within four ball spinning thread brass, specifically simulation and processing of experimental parameters as shown in Table 3.

TABLE III. SIMULATION PARAMETERS OF MACHINING

\begin{tabular}{|c|c|c|c|c|}
\hline $\begin{array}{c}\text { Tube Outer } \\
\text { Diameter } \\
/ \mathrm{mm}\end{array}$ & $\begin{array}{c}\text { Tube Blank } \\
\text { Diameter } \\
/ \mathrm{mm}\end{array}$ & $\begin{array}{c}\text { Inner Grooved } \\
\text { Copper Tube } \\
\text { Outside } \\
\text { Diameter } / \mathrm{mm}\end{array}$ & $\begin{array}{c}\text { Internal } \\
\text { Thread } \\
\text { Number }\end{array}$ & $\begin{array}{c}\text { Spinning } \\
\text { Depth /mm }\end{array}$ \\
\hline$\phi 6.6$ & $\phi 5.6$ & $\phi 6$ & 60 & 0.3 \\
\hline
\end{tabular}

It established a three-dimensional finite element model based on the above data shown in Fig. 3, The ball and core head are hard and the strength compared to the inner grooved copper tube, there is hardly occurs plastic deformation during the spinning process. So the simulation is defined as a rigid body parsed. During the spinning process of the inner grooved copper tube since the inner grooved copper tube cross-section meet axial symmetry. In order to improve the efficiency of the simulation, therefore, the model reduces to $1 / 4$ rotationally symmetrical structure, three-dimensional model shown in Fig. 4 (a), the symmetric axis is the axis of inner grooved copper tube. To ensure the 
accuracy of simplified model, we need to ensure that the ball 1 spin out of the plane of symmetry, the ball 2 just screwing another symmetry plane. Multidentate core and the ball including the inner grooved copper tube spin forming process is defined as a discrete rigid, but do not need to meshing for participate in the calculation. Inner grooved copper tube using hexahedral meshing unit and load rotational symmetry boundary conditions shown in Fig .4 (b). Numerical simulation process using the ALE meshes adaptive technology to meet the situation for the mesh major displacement of large deformation during the spinning process. Numerical simulation of inner grooved copper tube spinning, and made the following assumptions:

- Isotropic and homogeneous material;

- Ignore the influence of gravity;

- The ball is pure rolling during the spinning process.
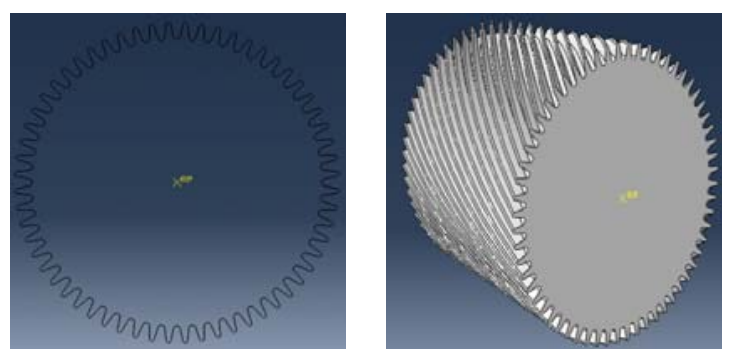

Figure 3. Schematic diagram of multi-tooth mandrel model

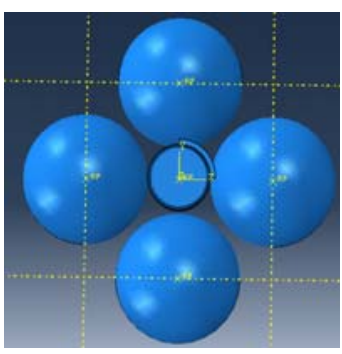

(a)

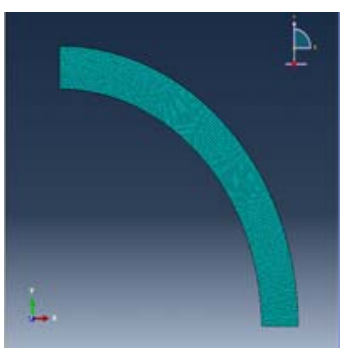

(b)
Figure 4. Alveolar 3D elastic-plastic finite element model

\section{FINITE ELEMENT SIMULATION ANALYSIS}

In this paper, the principle of finite element numerical simulation is based on a fixed part of the argument, changes spinning mold speed, so evident its variation. In the spinning process with increasing spin speed, the feed ratio decreasing, would result in an expansion of a workpiece, pipe wall thickness is too thin it will face wrinkling in the outer tubular member. Spinning speed decreases, the feed ratio $f$ increases, is conducive fittings film and increase productivity, but as the feed ratio increases, the inner tube diameter, wall thickness deviation will increase, and the spin pressure will be followed increases, This leads to the outer surface of the pipe leaving visible thread traces, the tube surface roughness decrease. Simulation process parameters are shown in Table 4.
TABLE IV. THE PROCESSING PARAMETERS OF SIMULATION PROCESS

\begin{tabular}{|c|c|c|c|}
\hline $\begin{array}{c}\text { Tube outer } \\
\text { diameter } \\
/ \mathrm{mm}\end{array}$ & $\begin{array}{c}\text { Tube blank } \\
\text { diameter } \\
/ \mathrm{mm}\end{array}$ & $\begin{array}{c}\text { Inner diameter of } \\
\text { inner screw pipe } \\
/ \mathrm{mm}\end{array}$ & $\begin{array}{c}\text { Ball } \\
\text { diameter } \\
/ \mathrm{mm}\end{array}$ \\
\hline$\phi 6.6$ & $\phi 5.6$ & $\phi 6$ & $\phi 8$ \\
\hline $\begin{array}{c}\text { Internal thread } \\
\text { number }\end{array}$ & $\begin{array}{c}\text { Spinning } \\
\text { Depth } \\
/ \mathrm{mm}\end{array}$ & $\begin{array}{c}\text { Spinning speed } \\
\left(\times 10^{3}\right) \mathrm{r} / \mathrm{min}\end{array}$ & $\begin{array}{c}\text { Drawing } \\
\text { Speed } \\
\mathrm{mm} / \mathrm{s}\end{array}$ \\
\hline 60 & 0.3 & $10,12,18,24$ & 80 \\
\hline
\end{tabular}

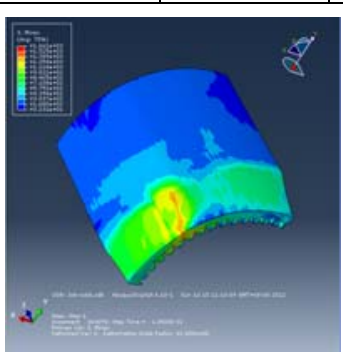

(a) $n=10000 \mathrm{r} / \mathrm{min}$

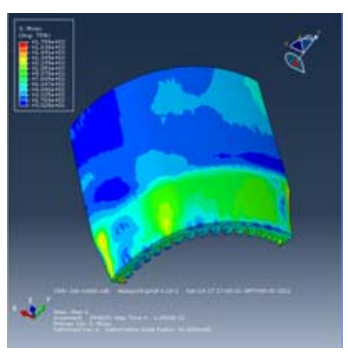

(c) $n=18000 \mathrm{r} / \mathrm{min}$

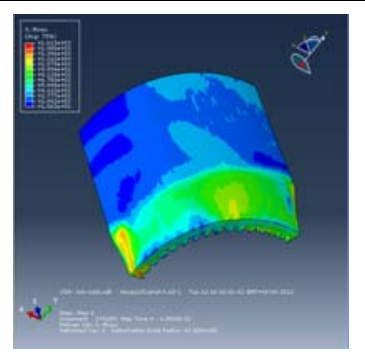

(b) $n=12000 \mathrm{r} / \mathrm{min}$

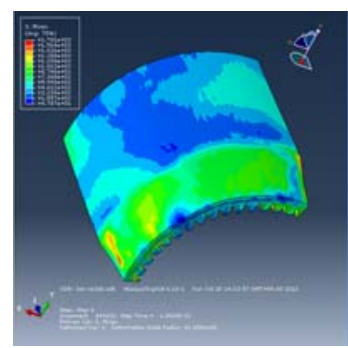

(d) $n=24000 \mathrm{r} / \mathrm{min}$
Figure 5. Stress distribution nephogram inner groove copper tube in different spinning speed forming

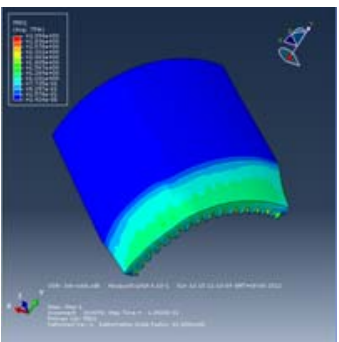

(a) $n=10000 \mathrm{r} / \mathrm{min}$

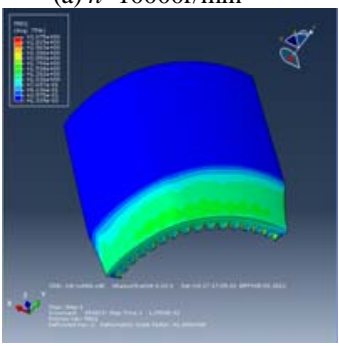

(c) $n=18000 \mathrm{r} / \mathrm{min}$

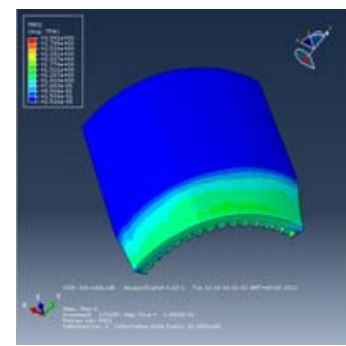

(b) $n=12000 \mathrm{r} / \mathrm{min}$

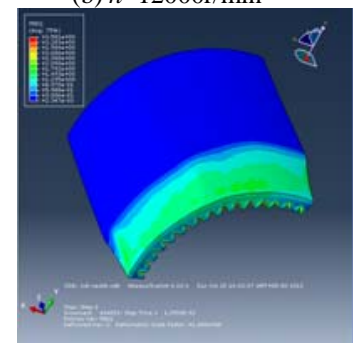

(d) $n=24000 \mathrm{r} / \mathrm{min}$
Figure 6. Stress distribution nephogram inner groove tube pipe in different spinning speed forming 
Fig. 5 and Fig. 6, respectively stress, strain contours of inner grooved copper tube during different spin speed. From Fig. 5(a) and (b), the equivalent stress of inner grooved copper tube decreases with the increase of spinning speed. This is because as the spinning speed increases in a certain range feed ratio decreases, resulting inner grooved copper tube suffered spin pressure reduced. From Fig. 5(c), (d) may also come to this variation. As can be seen from Fig. 6 inner grooved copper tube equivalent strain increases with spinning speed increases. With increasing spin speed has improved the efficiency for inner grooved copper tube forming. When the spinning speed $n$ is $12000 \mathrm{r} / \mathrm{min}$, the maximum value of the maximum equivalent stress and equivalent strain is the smallest of the four spinning speed. When the spinning speed is $10000 \mathrm{r} / \mathrm{min}, 18000 \mathrm{r} / \mathrm{min}$ and $24000 \mathrm{r} / \mathrm{min}$, and so the effects of stress, strain value than $12000 \mathrm{r} / \mathrm{min}$ larger. The excessive equivalent stress and the equivalent strain can cause the accumulation and uplift of the inner grooved copper tube. Therefore, to ensure other process parameters unchanged, spinning speed $n$ is 12000 $\mathrm{r} / \mathrm{min}$ inner grooved copper tube molding at best.

\section{CONCLUSIONS}

Through the establishment of three-dimensional finite element model of inner groove copper tube ball spinning forming process, and to understand the forming process of inner groove copper tube in ball spinning, the change of stress, strain and forming process.

Method with the single variable analysis of the influence for the process parameters on the inner groove copper tube into the tooth quality. Forming an inner groove copper tube spinning process, along with the increase of the spinning speed, the equivalent inner straight groove pipe stress increases gradually, the strain is relatively level increases.

The ball on the simulation of the principle for diameter of deformation instability provides reference to effectively control the actual production, as well as the real machining process to improve the instability phenomenon provides basis. This paper is not perfect, should be combined with the core head size, position were considered.

\section{ACKNOWLEDGMENT}

This work was supported by Industry Project of Qiqihar City (Grant No. GYGG-201101).

\section{REFERENCES}

[1] Yang Yingli, GuoDizi, etc, “Advances in technology of spinning”, Aeronautical Manufacturing Technology, 2007, Supplement.

[2] Zhaoyun Hao, Li Yanli, "Spinning Technology and Application," Machinery Industry Press, 2007, pp. 3-5, 74, 163.

[3] Jean-ouis Sauvonnet, Franck Delavaquerie, "Devices for the grooving of tubes,” United State Patent, Patent Number: 5526663, 6, 18, 1996.

[4] Huang Mingyan, "Discussion the molding process of inner grooved copper tube,” Nonferrous Metals Industry, No. 5, 2001, pp. 46-47.

[5] Li Maosheng, Kang Dachang, etc, “Analysis and Calculation ball spinning process forming region of the contact pressure," Materials Science and Technology, Vol. 12, No. 2, 2014, pp. 125-128.
[6] ZHANG Shihong, Wujiang, "Thin-walled stainless steel tube Ball Spinning Forming Technology,” Forging Technology, Vol. 34, No. 1, 2012, pp. 60-64.

[7] Wang Miao, Wang Zhongtang, "Finite element analysis of the influence to axial feed on ball spinning of thin walled tubes," Shenyang University of Technology, Vol. 26, No. 2, 2007, pp. 30-33.

[8] Jiang Shuyong, Ren Zhengyi, Wu bin, Wu Guixiang, "General issues of FEM in backwoard ball spinning of thin-walled tubular part with longitudinal inner ribs," Transactions of Nonferrous Metals Society of China, Vol. 17, 2012, pp. 793-798.

[9] Jiang Shuyong, Ren Zhenyi, Li Chunfeng, Xue Kemin, "Role of ball size in backwoard ball spinning of thin-walled tubular part with longitudinal inner ribs,” Journal of Materials Processing Technology, Vol. 209, 2012, pp. 2167-2174.

[10] Jean-ouis Sauvonnet, Franck Delavaquerie, "Devices for the grooving of tubes ,’ United State Patent, Patent Number: 5526663, 6, 18, 1996.

[11] Zhang G L, Zhang S H, Zhang H Q, "The 3D finite element simulation of inner straight groove copper," Modern manufacturing engineering, No. 8, 2006, pp. 103-104. 